\title{
Pemaknaan Ilustrasi Berita Infografis Pada Media Online (Analisis semiotika pada Instagram CNBC Indonesia)
}

\author{
Muhammad Nur Arasid ${ }^{1}$, Ramita Hapsari ${ }^{2}$ \\ ${ }^{1}$ Universitas Gunadarma, arassiaras21@yahoo.com \\ ${ }^{2}$ Universitas Gunadarma, ramitahapsari2011@gmail.com
}

\begin{abstract}
Abstrak
Penelitian ini bertujuan untuk mengetahui makna dari ilustrasi berita infografis pada media online instagram CNBC Indonesia melalui analisis semiotik Roland Barthes yaitu makna dari denotasi, konotasi dan mitos yang terkandung didalam ilustrasi berita infografis. Penelitian ini menggunakan penelitian kualitatif dengan paradigma konstruktivisme. Teknik pengumpulan data dilakukan dengan cara dokumentasi, wawancara dan observasi terhadap ilustator atau pembuat ilustrasi dari berita yang akan dilakukan penelitian. Hasil penelitian menunjukan bahwa dalam setiap ilustrasi pada berita infografis CNBC Indonesia melalui Instagram akan selalu memiliki makna denotasi di dalamnya. Dari penelitian tersebut dapat disimpulkan untuk memahami sebuah ilustrasi kita dianjurkan untuk lebih melihat aspek denotasi dan konotasi dengan mitos sebagai pendamping.
\end{abstract}

Kata kunci : Infografis, Semiotik, Media Online, Illustrasi

\section{Abstract}

This study is intended to know the meaning of illustrated infographic news on Instagram online media CNBC Indonesia on semiotics analysis Roland Barthes namely meaning of denotation, conotation and myth containing in illustrated infographic news data collection technic is done by documentation, interviews and observation on illustrator of observing news. The observation result showing that each illustration on illustrated infographic news CNBC Indonesia on Instagram always have denotation meaning inside it. According by this research to understand we are recommended to see more on denotation and connotation aspecs than myth as supporting.

Key words : Infographic, Semiotics, Online Media, Illustration.

\section{PENDAHULUAN}

Seiring dengan kemajuan teknologi yang pesat, media online saat ini merupakan media yang banyak digemari masyarakat Indonesia terutama anak muda. Kita bisa dengan mudah mencari apa saja yang kita inginkan melalui media online. Bahkan beberapa media cetak maupun televisi pasti memiliki atau bahkan beralih ke media online. Media online juga merupakan sarana penyebaran informasi tercepat. Dengan adanya media online, informasi menjadi lebih aktual. Berbagai jenis penyampaian informasi dilakukan melalui media online. Guna untuk memanfaatkan teknologi saat ini, dan ditambah dengan beragam keahlian yang dimiliki manusia, kini terdapat jenis informasi berbasis infografis. Panduan 
Mengelola Media Online menurut Romli \& Syamsul (2012) adalah media massa yang tersaji secara online di situs web (website) internet. Media online dapat dengan mudah menyebar luaskan berita kepada khalayak umum dengan cepat, Dalam buku Here's the News yang dihimpun oleh Paul De Maeseneer, berita didefinisikan sebagai informasi baru tentang kejadian yang baru, penting, dan bermakna (signifikan), yang berpengaruh pada para pendengarnya serta relevan dan layak dinikmati oleh mereka Definisi lain dari berita, menurut Doug Newson dan James A. Wollert dalam Media Writing : News for the Mass Media (Sumadiria, 2005) mengemukakan dalam definisi sederhana, berita adalah apa saja yang ingin dan perlu diketahui orang atau lebih luas lagi oleh masyarakat Dengan melaporkan berita, media massa memberikan informasi kepada masyarakat mengenai apa yang mereka butuhkan.

Dalam era saat ini muncul jurnalisme online adalah praktek jurnalitik yang menggunakan channel internet. Jurnalisme online bisa jadi dilaksanakan oleh jurnalis profesional yang bekerja di sebuah situs berita formal dan bisa juga di lakukan oleh jurnalis warga yang menulis di blognya (hasfi,N 2010). Jurnalisme online ialah jurnalisme yang mengintegrasikan tiga fitur komunikasi yang unik: kemampuankemampuan multimedia berdasarkan platform digital, kualitas-kualitas interaktif, komunikasi-komunikasi online, dan fiturfitur yang ditatanya (Aryani, 2011).

Dalam jurnalistik online muncul inovasi atau elemen lain adalah Infografis, terutama pada media massa cetak dan media elektronik. Infografis mencakup presentasi visual yang dapat menjelaskan rangkaian cerita atau proses dari serangkaian data dengan menggunakan berbagai elemen seperti gambar, ilustrasi, tipografi, peta dan visualisasi (Dur, 2014). Infografis digunakan agar dapat mempermudah pembaca dalam memahami narasi sebuah berita maupun memahami proses sebuah penelitian ilmiah yang dipublikasikan. Tujuan infografis adalah sama dengan public speaking. Tujuan dari infografis dapat dibagi menjadi tiga kategori yaitu untuk menginformasikan, menghibur dan mempersuasi audiens sehingga audiens memberikan perhatian, menyempatkan untuk membaca, menyimpulkan dan melakukan aksi sesuai apa yang ada di dalam infografis (Krum, 2013).

Media CNBC Indonesia merupakan sebuah situs berita yang baru berdiri sejak tahun 2018 yang menyampaikan informasiinformasi, makro ekonomi, pasar modal, perbankan, industri keuangan lainnya, komoditas, manufaktur, ekonomi internasional serta politik, hukum dan hankam yang mempengaruhi dinamika ekonomi nasional secara komprehensif. CNBC Indonesia aktif dalam penyajian melalui website tapi juga melalui media sosial yang ditunjukan kepada para pembaca milenial, Oleh karena itu, CNBC Indonesia ingin menyampaikan peristiwa ekonomi kepada pembaca dengan banyak perspektif. Cara penyajiannya pun sederhana tapi kuat, agar pembaca mudah memahaminya, lewat teks, grafis, gambar bergerak dan videografis. Dengan menghadirkan infografis yang menarik dan kreatif, menjadi daya tarik tersendiri dalam mengundang pembaca.

Penyebaran Infografis ini juga memanfaatkan beberapa media sosial yang mendukung salah satunya yaitu media sosial Instagram. Media sosial adalah sebuah media online, dengan para penggunanya bisa dengan mudah berpartisipasi, berbagi, dan menciptakan isi meliputi blog, jejaring sosial, wiki, forum dan dunia virtual. Blog, jejaring sosial, dan wiki merupakan bentuk media sosial yang paling umum digunakan oleh masyarakat di seluruh dunia. Media sosial sebagai sebuah kelompok aplikasi berbasis internet yang membangun di atas dasar ideologi dan teknologi Web 2.0, dan yang memungkinkan penciptaan dan pertukaran user-generated content (Kaplan \& Michael, 2010). Beberapa contoh media sosial yang sedang berkembang saat ini yaitu Instragam, Karena media sosial Instagram lebih mempermudah dalam proses 
penyampaian informasi melalui visual dan memfokuskan pada para pembaca milenial.

Berdasarkan hal tersebut peneliti tertarik mengetahui makna dari grafis yang dibuat oleh tim grafis dari CNBC Indonesia dalam penyampaian berita untuk disajikan ke pembaca melalui analisis semiotika dari Roland Barthes dengan Denotasi, Konotasi dan mitos. Berdasarkan uraian di atas, maka dilakukan penelitian dengan judul skripsi Pemaknaan Ilustrasi Berita Infografis Pada Media Online (Analisis semiotika pada Instagram CNBC Indonesia).

\section{METODE PENELITIAN}

Metode yang digunakan dalam penelitian ini yaitu penelitian kualitatif, penelitian kualitatif adalah penelitian yang bermaksud untuk memahami fenomena tentang apa yang dialami oleh subjek penelitian misalnya perilaku, persepsi, motivasi, tindakan, dll secara holistik, dan dengan cara deskripsi dalam bentuk katakata dan bahasa, pada suatu konteks khusus yang alamiah dan dengan memanfaatkan berbagai metode alamiah (Moleong, 2012). Permasalahan yang akan dikaji oleh peneliti merupakan masalah yang bersifat sosial dan dinamis. Oleh karena itu, peneliti memilih menggunakan metode penelitian kualitatif untuk menentukan cara mencari, mengumpulkan, mengolah dan menganalisis data hasil penelitian tersebut. Penelitian kualitatif ini dapat digunakan untuk memahami interaksi sosial, misalnya dengan wawancara mendalam sehingga akan ditemukan pola-pola yang jelas. Objek penelitian ilmiah ini adalah infografis ilustrasi dari CNBC Indonesia,

Teknik pengumpulan data merupakan langkah yang paling strategis dalam penelitian, karena tujuan utama dari penelitian adalah mendapatkan data (Sugiyono, 2013). Untuk memudahkan dalam proses pengumpulan data yang tepat dan akurat, diambil beberapa teknik pengumpulan data yaitu sebagai berikut: Teknik Wawancara, Menurut Esterberg dalam Sugiyono (2013) wawancara merupakan pertemuan dua orang untuk bertukar informasi dan ide melalui tanya jawab, sehingga dapat dikontruksikan makna dalam suatu topik tertentu. Teknik Pengamatan/Observasi, Sutrisno Hadi dalam Sugiyono (2013) mengemukakan bahwa, observasi merupakan suatu proses yang kompleks, suatu proses yang tersusun dari berbagai proses biologis dan psikhologis. Dua di antara yang terpenting adalah prosesproses pengamatan dan ingatan. Teknik Dokumentasi, Menurut Sugiyono (2013) dokumen merupakan catatan peristiwa yang sudah berlalu. Dokumen bisa berbentuk tulisan, gambar, atau karya-karya monumental dari seorang. Dokumen yang berbentuk tulisan misalnya catatan harian, sejarah kehidupan (life histories), ceritera, biografi, peraturan, kebijakan. Dokumen yang berbentuk gambar misalnya foto, gambar hidup, sketsa dan lain-lain. Dokumen yang berbentuk karya misalnya karya seni, yang dapat berupa gambar, patung, film dan lain-lain. Studi dokumen merupakan pelengkap dari penggunaan metode observasi dan wawancara dalam penelitian kualitatif.

\section{PEMBAHASAN}

Penelitian ini membahas tentang makna yang ada dalam infografis yang ada di Instagram, dalam melakukan wawancara peneliti melakukan wawancara yang dilaksanakan di kantor CNBC Indonesia di gedung Transmedia Lt. 3A Jl. Kapten P. Tendean Kav 12-14a Mampang Prapatan, Jakarta Selatan untuk mengetahui makna ilustrasi yang terkandung di dalam infografis tersebut dan juga mengetahui makna sebenarnya.

Gagasan Barthes ini dikenal dengan "order of signification", mencakup denotasi (makna sebenarnya sesuai kamus) dan konotasi (makna ganda yang lahir dari pengalaman kultural dan personal) Barthes juga melihat aspek lain dari penandaan yaitu "mitos" yang menandai suatu masyarakat. "Mitos" menurut Barthes terletak pada tingkat kedua penandaan, jadi setelah terbentuk sistem signsignifier-signified, tanda tersebut akan menjadi penanda baru yang kemudian memiliki petanda kedua dan membentuk tanda baru. Jadi, ketika suatu tanda yang 
memiliki makna konotasi kemudian berkembang menjadi makna denotasi, maka makna denotasi tersebut akan menjadi mitos.

Dalam hasil penelitian yang sudah dilakukan peneliti terdapat Denotoasi, Konotasi dan Mitos yang terkandung di dalam ilustrasi dari berita infografis yang didukung oleh teknik wawancara mendalam yang dilakukan peneliti kepada pembuat ilustrasi dari infografis tersebut dengan mengetahui makna sebenarnya dari pembuat.

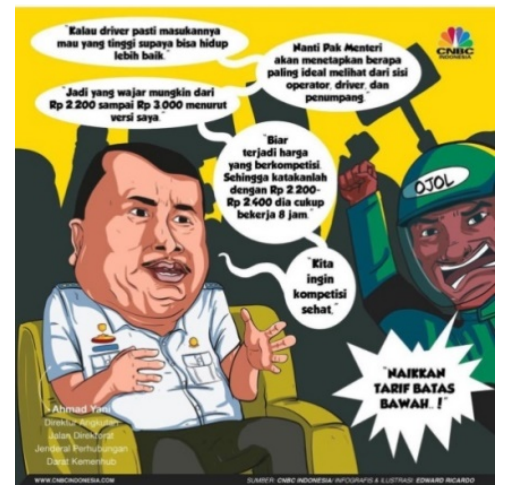

Gambar 1. berita polemik tarif ojek online

Dari gambar pertama yaitu berita polemik tarif ojek online, peneliti membagi tiga potongan gambar keseluruhan yang dijelaskan melalui tabel diatas dengan potongan gambar pertama mempunyai denotasi yaitu bapak Direktorat Jendral Perhubungan Ahmad Yani sedang duduk disofa dan mempunyai Konotasi bahwa dalam pakaian dinas tersebut adalah ciri khas dari Kementrian Perhubungan dan duduk disofa melambangkan posisi dan jabatan yang dipunyai serta Mitos bahwa dalam pakaian dinas dari kementrian perhubungan dengan pakaian dinas lain berbeda beda. Dalam konotasi tersebut masyarakat akan mengetahui jika seseorang menggunakan pakaian dinas kementrian perhubungan maka akan tahu bahwa seseorang tersebut bekerja dan berkaitan dengan kementrian perhubungan maka konotasi tersebut menjadi mitos dalam illustrasi ini.

Potongan gambar yang kedua mempunyai denotasi seorang driver ojek online memakai jaket dan helm hijau dan mempunyai Konotasi bahwa Jaket dan helm hijau mengingatkan masyarakat bahwa pakaian tersebut merupakan ciri khas pengemudi ojek online dengan gesture tangan mengangkat ke atas dengan menggempalkan tangan dengan ekspresi wajah yang berteriak melambangkan seseorang marah.atau emosi sedangkan mempunyai Mitos bahwa dapat ditemukan dalam bentuk raut muka, bahasa tubuh, yang jelas ada pada ilustrasi tersebut dengan bentuk muka yang sedang berteriak dan gempalan tangan kea rah atas merupakan ekspresi dari kemarahan dan dalam pakaian dengan warna hijau masyarakat akan menjadi tahu bahwa helm dan pakaian yang berwarna hijau merupakan lambang dari ojek online, inilah yang membuatnya menjadi mitos.

Potongan ketiga dari ilustrasi tersebut mempunyai denotasi Sekumpulan siluet orang mengangkat tangan dan juga memegang papan dan mempunyai Konotasi orang yang sedang berdemo serta mempunyai Mitos ditemukan dalam sekumpulan orang dengan bentuk gesture tubuh yang simbolkan sebagai Unjuk rasa atau Demonstrasi.

Dari keseluruhan gambar yang ada mempunyai denotasi bahwa memperlihatkan dua orang tokoh lelaki yang berada didepan, salah satu tokoh tersebut adalah Direktur Jendral Perhubungan Angkutan Jalan yaitu Ahmad Yani yang sedang duduk disofa dan tokoh lain mewakili para pengemudi ojek online yang berbicara untuk tarif ojek online, menggunakan jaket hijau dan helm hijau. Dibelakang kedua tokoh tersebut terdapat siluet para pengemudi ojek online yang sedang berdemo dengan mengangkat tangan ke atas, dan mempunyai konotasi yang sesuai dengan pembuat dari ilustrasi tersebut yaitu Dari ilustrasi ini bisa kita lihat ada dua orang tokoh yang sedang berbicara dengan berbeda gesture tubuh dengan latar belakang para pendemo. Konotasi dari ilustrasi ini yaitu menggambarkan kondisi saat berlangsungnya aksi unjuk rasa dimana Direktur Angkatan Jalan yaitu Ahmad Yani 
duduk disofa menggambarkan posisi dan jabatan sedangkan tokoh pengemudi ojek online digambarkan berdiri menggambarkan situasi yang terjadi dimana para pengemudi ojek online ujuk rasa. Untuk menggambarkan situasi unjuk rasa maka dibelakang kedua tokoh diilustrasikan sekumpulan orang dengan gesture unjuk rasa dengan membawa papan dan mengangkat tangan. Dan background kuning dibelakang menggambarkan situasi polemik untuk mendapatkan perdamaian antara pendemo dan pemerintah. pada mitos gambar pertama dari gambar keseluruhan dapat disimpulkan bahwa terdapat mitos pada ketiga potongan gambar, yaitu pada pakaian yang digunakan oleh Ahmad Yani yang berpakaian khas kementrian perhubungan, pakaian yang dikenakan ojek online yang berwarna hijau dan gesture muka maupun gesture tangan yang ditunjukan oleh ojek online dan demonstran dibelakang. Masyarkat akan tahu bahwa berpakain khas seperti Ahmad Yani merupakan ikon atau simbol dari kementrian perhubungan dan pakaian dan helm hijau merupakan ikon atau simbol dari ojek online, dari gesture tubuh mengangkat tangan dengan membawa papan akan menjadi konotasi bahwa sedang berunjuk

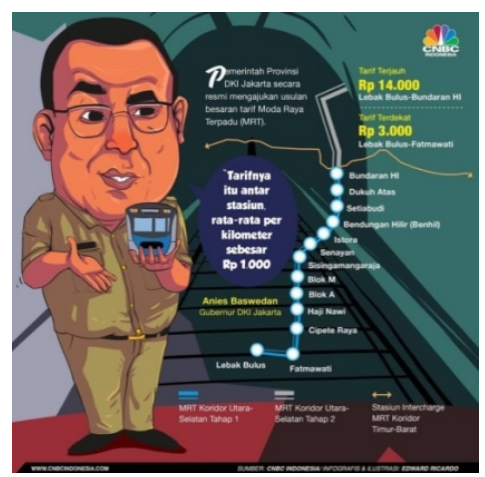

rasa dan menjadi mitos.

Gambar 2. berita polemik tarif MRT Jakarta

Dari gambar kedua yaitu berita polemik tarif MRT Jakarta, peneliti membagi tiga potongan gambar keseluruhan yang dijelaskan melalui tabel diatas dengan potongan gambar pertama mempunyai Denotasi yaitu Gubernur DKI Jakarta Anies Baswedan berada diatas panggung dengan memegang lokomotif dari MRT, dan mempunyai Konotasi Gubernur DKI Jakarta Anies Baswedan beridi di atas panggung dengan pakaian dinas Pegawai Negri Sipil (PNS) dengan memegang lokomotif MRT. Dengan berdiri nya di atas panggung Gubernur ingin menyampaikan pesan kepada semuanya.

Dari potongan gambar kedua mempunyai Denotasi yaitu Gubernur Jakarta memegang Gerbong depan dari MRT Jakarta, dan mempunyai Konotasi Gerbong depan lokomotif MRT DKI Jakarta berwarna biru pada rangkaian gerbong dari kereta MRT Jakarta yang saat ini beroperasi dengan nama Ratangga oleh Gubernur Jakarta dan dengan memegang gerbong depan lokomotif Gubernur memeliki kuasa untuk mensetujui tarif MRT yang berlaku di Jakarta. Sedangkan untuk Mitos yang terkandung dari Konotasi tersebut kereta dari MRT Jakarta memiliki nama Ratangga, nama Ratangga diambil dari kitab Arjuna Wijaya dan Sutasoma Mpu Tantular. Nama Ratangga dalam bahasa Sansekerta dimaknai sebagai "roda" atau "kereta". Sementara dari dalam kitab kuno Ratangga adalah kereta perang. Dalam hal ini diharapkan Ratangga mampu mempunyai kekuatan yang berada dalam kereta perang dan mempunyai perjuangan. Dalam melihat gerbong MRT Jakarta masyarakat akan mengenal dengan nama Ratangga.

Dalam potongan gambar yang terakhir yaitu ke tiga mempunyai denotasi Sebuah jalur rel bawah tanah MRT dengan Terowongan besar berwarna gelap. Dan mempunyai Konotasi Moda Raya Terpadu identik dengan jalur kereta bawah tanah, dimana dalam bawah tanah dibuatkan jalur rel dengan terowongan besar yang berada dibawah. Maka dalam pewarnaan di buatkan ilustrasi dengan situasi yang mendekati. Serta Mitos Pada ilustrasi di samping telah dianggap masyrakat sebagai mitos yaitu dapat ditemukan bahwa MRT Jakarta berada di rel yang dibangun dibawah tanah berbeda dengan transportasi kereta umumnya yaitu Kereta Rel Listrik atau biasa dikenal dengan KRL berada pada jalur rel darat dan Light Rail Transit atau LRT berada pada jalur rel laying. Pada kenyataan nya mitos di 
samping telah dianggap masyrakat sebagai konotasi dan menjadikan nya mitos.

Dalam keseluruhan ilustrasi dari infografis tersebut mempunyai Denotasi Gubernur DKI Jakarta Anies Baswedan mengenakan pakaian dinas berwarna coklat diatas panggung dengan memegang lokomotif MRT dengan latar belakang suasana rel MRT dengan terowongan yang digambarkan berwarna gelap. Dan mempunyai Konotasi Gubernur dki Jakarta yaitu Anis baswedan yang sedang memakai baju dinas berwarna coklat PNS dengan rapih berdiri diatas panggung sedang memegang MRT menandakan kekuasaan akan hal itu sesuai dengan isi dari berita bahwa Anies Baswedan telah disepakatinya tarif mrt yang berbeda dengan rapat pimpinan sebelumnya. Dan dibelakang ada lorong dan jalur rel berwarna gelap. Bahwa MRT itu berada di bawah tanah yang menandakan bahwa suasana gelap dan juga kegelapan yang identik dengan terowongan. Untuk layout font tersebut sesuai ya dengan layout rute kereta yang biasa kita temui, dimana rute tersebut sesuai dengan jalur MRT. Pada gambar kedua tentang polemik tarif MRT didapatkan mitos dari keseluruhan gambar kesimpulan mitos yang sudah dibagi menjadi tiga bagian, mitos keseluruhan dari gambar mempunyai mitos bahwa MRT Jakarta mempunyai nama Ratangga yaitu bahasa dari sangsakerta yang di artikan sebagai kereta perang, bahwa masyarkat akan mengenal MRT tersebut dengan nama Ratangga dan pada mitos lain bahwa masyarakat akan selalu mengingat bahwa MRT merupakan kereta bawah tanah, berbeda dengan transportasi kereta umumnya yaitu Kereta Rel Listrik atau biasa dikenal dengan KRL berada pada jalur rel darat dan Light Rail Transit atau LRT berada pada jalur rel layang. Pada kenyataan nya mitos di samping telah dianggap masyrakat sebagai konotasi dan menjadikan nya mitos.
Gambar 3. berita polemik tarif Angkutan Udara

Dari gambar ketiga yaitu berita polemik tarif Angkutan Udara, peneliti membagi tiga potongan gambar keseluruhan yang dijelaskan melalui tabel diatas dengan potongan gambar pertama mempunyai Denotasi yaitu Pesawat terbang dengan situasi terbang naik keatas. Dan Konotasi ilustrasi tersebut Pesawat terbang berada di udara dengan situasi naik keatas melambangkan bahwa terjadi kenaikan pada tarif tinggi pesawat terbang diberbagai daerah dindonesia. Sedangkan untuk Mitos yaitu dari konotasi tersebut maka dapat disimpulkan mitos bahwa pesawat terbang adalah transportasi yang mewah dan mahal dari transportasi yang ada di Indonesia.

Sedangkan untuk potongan gambar ke dua mempunyai Denotasi Uang rupiah pecahan tertinggi yaitu seratus ribu rupiah menjadi warna dari pesawat. Dan mempunyai Konotasi dalam polemik tarif transportasi udara menjadi kian mewah dan paling tinggi dari segi tarif transportasi yang bisa digunakan di Indonesia maka digambarkan lah pecahan paling tinggi yaitu diillustrasikan pecahan seratus ribu rupiah. Sedangkan untuk mitos dalam uang seratus ribu rupiah adalah mata uang tertinggi dalam pecahan rupiah maka menjadikan sebuah simbol kedudukan paling tinggi dan mahal dalam menggambarkan suatu harga yang ada. itulah mengapa konotasi menjadi mitos.

Dalam potongan gambar yang ke tiga dan terakhir mempunyai Denotasi Pesawat berbentuk potongan puzzle. Dan mempunyai Konotasi menggambarkan bahwa pesawat berbentuk puzzle atau potongan-potongan yang dapat digabungkan menandakan posisi posisi dari daerah inflasi tarif terendah pada bagian bawah pesawat 
dengan kenaikan tarif 12 persen, hingga tertinggi berada pada potongan depan pesawat dengan kenaikan 32 persen. Puzzle pesawat terdapat 10 potongan-potongan sesuai dengan 10 daerah dengan kenaikan tarif tertinggi.

Dari penggabungan gambar ilustrasi tersebut mempunyai Denotasi Pesawat terbang dengan latar uang pecahan tertinggi seratus ribu rupiah dengan posisi terbang naik keatas dengan awan disekitar. Dan mempunyai Konotasi Menggambarkan pesawat sedang naik ke atas menandakan bahwa ada kenaikan harga yang terjadi disetiap daerah sesuai dengan berita yang ditampilkan. Dan pesawat tersebut di gambarkan dengan puzzle untuk menandakan daerah-daerah tersebut. Dibuat puzzle sesuai dengan kota yang ada maka puzzle nya ada 10 dan juga diurutkan sesuai kenaikan paling rendah hingga paling tinggi yang berada di ujung atas pesawat. Ada lagi kenapa disitu ada mata uang tertinggi yaitu pecahan seratus ribu rupiah dikarenakan dalam polemik tarif udara menjadi kian mewah dan paling tinggi dari segi tarif transportasi yang bisa digunakan di Indonesia maka digambarkan lah pecahan paling tinggi yaitu seratus ribu rupiah. Untuk layout font digambarkan awan karena awan merupakan symbol dari langit dimana pesawat terbang mengudara di langit., dan ada background dibelakang berwarna gelap mengambarkan situasi langit mendung dan suasana masyarkat yang tidak setuju, juga agar terlihat lebih kontras dan menonjol. Pada gambar ketiga tentang polemik tarif angkutan udara, Pada potongan gambar tersebut terdapat dua bagian potongan yang menggambarkn mitos didalam ilustrasi berita infografis, dapat disimpulkan mitos nya pada gambar keseluruhan yaitu pesawat merupakan moda transportasi mahal yang ada di indonesia yang selalu dianggap pada masyrakat. Berkaitan tentang isi berita tersebut, pada potongan puzzle pesawat di ilustrasikan dengan pecahan mata uang tertinggi di Indonesia yaitu seratus ribu rupiah. Dalam uang seratus ribu rupiah adalah mata uang tertinggi dalam pecahan rupiah maka menjadikan sebuah simbol kedudukan paling tinggi dan mahal dalam menggambarkan suatu harga yang ada. itulah mengapa konotasi menjadi mitos.

Dalam setiap ilustrasi yang ada akan selalu ada denotasi dan konotasi, karena konotasi selalu bergabung dengan mitos namun berbeda dengan kedua makna diatas maka mitos tidak selalu ada dalam sebuah ilustrasi, terkadang sebuah ilustrasi memiliki ketiga makna yaiut denotasi, konotasi dan mitos tapi banyak ilustrasi yang hanya memiliki makna denotoasi dan konotasi saja. Karena itu untuk memahami sebuah ilustrasi kita dianjurkan untuk melihat aspek denotasi dan konotasi dengan mitos sebagai pendamping jika ada.

\section{REFERENSI}

Aryani, R. (2011). Konsep Penyajian Jurnalisme Online di. www. Antararnews.com. UIN Syarif Hidayatullah.

Dur, B. I. U. (2014). Data visualization and infographics in visual communication design education at the age of information. Journal of Arts and Humanities, 3(5), 39-50.

Kaplan, M. A., \& Michael, H. (2010). "Users of the world, unite! The challenges and opportunities of social media." Business Horizons. https://doi.org/10.1016/j.bushor.200 9.09.003

Krum, R. (2013). Cool Infographics: Effective Communication with Data Visualization and Design. Indiana: John Wiley \& Sons, Inc.

Moleong, L. (2012). Metodologi Penelitian Kualitatif. Bandung: Rosda Karya.

Romli, M., \& Syamsul, A. (2012). Panduan Mengelola Media Online. Bandung: Nuansa Cendikia.

Sumadiria, A. H. (2005). Jurnalistik 
Indonesia, Menulis Berita dan Feature, Panduan Praktis Jurnalis Profesional. Bandung: PT. Remaja Rosdakarya.

\section{BIODATA PENULIS}

Nama Muhammad Nur Arasid, Tempat, Tanggal Lahir Depok, 31 Juli 1997 Penulis merupakan mahasiswa tingkat akhir pada program studi Ilmu Kounikasi, universitas Gunadarma.

Ramita Hapsari, S.I.Kom., M.Si. Merupakan dosen tetap di Universitas Gunadarma. 